\title{
Increasing Teacher Engagement in Innovative Learning Environments: Understanding the Effects of Perceptions of Risk
}

\author{
Tamara K. Jones and Deidre M. Le Fevre
}

\begin{abstract}
School systems around the world are investing in a transition to Innovative Learning Environments (ILEs). Many policies and resources are being directed towards this change. However, if the effects of innovative educational initiatives are to be positive for our students, the onus will ultimately be on teachers to integrate learner-centric pedagogies and digital technologies in flexible learning environments. Educational innovations are dependent upon what teachers think, feel and do in classrooms (Fullan 2001). This chapter examines how teacher perceptions can influence their engagement in ILEs.
\end{abstract}

Internationally, many education policies are promoting ILEs as a way of better meeting the needs of twenty-first-century learners. The introduction of flexible learning spaces is intended to provide teachers with opportunities to employ creative and innovative teaching practices that can lead to more robust, continuously improving communities of practice. For this shift to occur teachers will need to change how they think and how they teach, and this is likely to generate a range of reactions. Reactions to change may include "perceptions of risk", which recent research suggests may be a fundamental barrier to change (Jones, 2014; Le Fevre, 2014; Twyford, Le Fevre, \& Timperley, 2017). This chapter examines what perceptions of risk are and why they may be prevalent in the context of developing ILEs. Our view is that if researchers, policymakers, educational leaders and practitioners are aware of, and responsive to teachers' feelings of uncertainty, this may mitigate teachers' perceptions of risk. Mitigating teachers' perceptions of risk may result in teachers adapting their practice to maximise the learning opportunities possible in ILEs.

Shifts towards ILEs have been informed by learning theories which reveal traditional teacher-centred transmission models of teaching do not align with how people learn (Dumont, Istance, \& Benavides, 2010). An OECD ILE framework has been developed with seven guiding learning principles "proposed as fundamental to all

T. K. Jones · D. M. Le Fevre ( $\varangle)$

The University of Auckland, Auckland, New Zealand

e-mail: tel1005@aucklanduni.ac.nz

W. Imms and T. Kvan (eds.), Teacher Transition into Innovative Learning Environments, https://doi.org/10.1007/978-981-15-7497-9_7 
schools and learning settings as offering the building blocks of design, improvement and innovation" (OECD, 2017, p. 22). The guiding principles focus on the learners as the core participants, encourages their active engagement and stresses the social nature of learning. The principles also focus on the importance of recognising individuals' differences, motivations and emotions.

In order to fully realise ILEs, changes to physical learning environments are requisite. Flexible learning spaces are identified as a key resource in ILEs, and are intended to be motivating, facilitate engagement and recognise the social nature of learning. However, Fielding and Nair (2005) claim flexible learning spaces will only enable more innovative approaches to learning if the teachers have an understanding of the guiding principles of ILEs and a flexible, risk-taking attitude.

\section{The Concept of Risk}

The term risk has been used in numerous ways and in various contexts for many years. In the corporate world, the term "risk" is commonplace; risk management, capital risk and systematic risk all focus on the identification, assessment and prioritisation of commercial risk (Stulz, 1996). In the education sector, the concept of risk is only beginning to be acknowledged in the context of working to understand processes of innovation and change.

A broad definition of risk includes loss, significance of loss and uncertainties (Aven \& Renn, 2009; Ponticell, 2003; Trimpop, 1994). Loss, which can be performance related, social, psychological or status related is considered foundational to risk-taking (Ponticell, 2003) and is often discussed in relation to the significance or severity of potential loss to a person (Aven \& Renn, 2009). If a teacher perceives certain actions may lead to a greater severity of loss, then he or she will correspondingly react with higher levels of caution. The third element associated with risk is the nature of the uncertainty of an outcome. Uncertainty is inherent to perceptions of risk (Trimpop, 1994).

\section{Why an Understanding of Perceptions of Risk Matters}

Teachers are commonly expected to be "doing something that others are suggesting they do" (Richardson, 1990, p. 11). Some teachers willingly trial or implement these suggestions for change, while many others avoid engagement, or are accused of being resistant to, or resilient to change. Forms of resistance such as refusal or withdrawal are commonly reported, yet there appears to be little agreement on either the cause or nature of what is commonly called "teacher resistance", or how to respond to such reactions effectively. The most likely outcomes of what is often perceived 
as resistance is that it gets in the way of enabling teachers to effectively explore innovation and change.

More recent research recognises that accusing teachers of being resistant to change may be counterproductive to developing a culture of collaborative and sustainable improvement. Rather than blaming teachers, it is important to understand the challenges they experience in order to better support them. Research by Jones (2014), Le Fevre (2014), and Twyford (2016) suggests that teachers' perceptions of risk may influence their engagement in educational change. What might look like resistance may, in fact, be teachers' perceptions of risk. Perceptions of risk which include feelings of uncertainty about change and feelings of vulnerability in relation to engaging in change may cause people to be reluctant to engage in change (Le Fevre, 2014). For example, teachers may perceive engaging in ILEs to be risky to their identity as an educator, or they may lack an understanding of the guiding principles of ILEs and be uncertain about the outcomes for their students' learning.

\section{Theories of Risk-Taking in Education}

Why focus on perceptions of risk? Understanding how and why people react to change in the ways they do is essential if we are to support people to change. Theories about risk and risk-taking are powerful levers in seeking to understand how and why teachers react to change in the ways they do. For example, research indicates perceptions of risk can interrupt teachers' engagement in change initiatives and may be "a significant roadblock to engaging in educational change" (Le Fevre, 2014, p. 64).

Research has suggested that the degree of teacher willingness to engage in change initiatives may be a personal trait and stem from personal practical theories or an individual teacher's risk attitude. Teachers develop strong identities and "personal practical theories" throughout their careers (Maaranen, Pitkäniemi, Stenberg, \& Karlsson, 2016). Personal practical theories are formed through experience and reflection; they forge a teacher's identity and with more teaching experience become ingrained; they are "something they just do, and are a part of who they are as teachers" (Levin, He, \& Allen, 2013, p. 213). Personal practical theories are significant when we come to consider what happens when teachers are expected to change the way they teach. The unquestioning acceptance of ingrained personal practical theories of teaching may result in teachers closing themselves off to learning how to work in ILEs. However, it may also be that an individual teacher's risk attitude influences risk-taking behaviour (Baylor \& Ritchie, 2002; Le Fevre, 2014), which Baylor and Ritchie (2002) claim is difficult to influence.

An alternate theory of risk-taking in education is that groups and cultures, which have diverse social principles, guide risk behaviour and judgement of what is deemed a risk and who should be allowed to take risks. Rosa (1998) suggests that, "since identification of risks is entirely a social process, risks do not exist in objective reality, 
but in the collective consciousness of cultures" (Rosa, 1998, p. 21). What one school culture perceives as a risk may not be deemed a risk for another.

While ILEs may have many affordances for more effective pedagogies, their success will depend on teachers taking risks to exploit their potential. Understanding how affective factors such as perceptions of risk, or feelings of uncertainty can cause teachers to react is an important area for research (Jones, 2018) and is the focus of the empirical research explored in this chapter.

To capture the complex connections between school leaders' and teachers' understandings of ILEs, and their reactions to expectations to transition to ILEs, the first author employed a three-school case study approach. The research also investigated forms of support that mitigated teachers' perceptions of risk and enabled teachers to work collaboratively in ILEs. The research explored three key questions:

(1) What are school leaders' and teachers' understandings of Innovative Learning Environments?

(2) How do teachers react to expectations to engage in Innovative Learning Environments?

(3) What forms of support do teachers perceive enable them to develop their understanding of Innovative Learning Environments, and engage in innovative practices?

\section{Methods}

The qualitative empirical study this chapter draws on involved three New Zealand elementary schools. Teachers in the three schools selected were expected to explore or implement ILE teaching approaches. The data collection methods included semistructured interviews, observations, document analysis of online teacher journaling and publicly available school documentation.

Interviews were conducted with eighteen teachers from the three schools twice during the year. During the initial interview, participants were asked to explain their understanding of ILEs, share innovative practices they had recently implemented, and discuss what had supported or challenged them to change their practice. In the follow-up interview participants were asked to identify any changes in their understanding of ILEs, discuss their feelings about being expected to engage in innovative practices, and share professional learning opportunities that had impacted on their understanding of, and practice in ILEs. Four school leaders were also interviewed to ascertain their understanding of ILEs and gain an insight into their processes for supporting teachers to transition into ILEs.

Prolonged engagement and numerous observations in the field provided an understanding of how teachers had developed their perceptions of ILEs and why they reacted the way they did to expectations to engage in innovative practices. Data were analysed using an inductive and deductive thematic approach and coded using NVivo. Thematic maps were developed based on teachers' and leaders' understandings of ILEs, leaders' expectations of teachers to engage in ILEs, teachers' reactions 
to the expectations, and to the professional support provided. Member checking, triangulation of data, negative case analysis and inter-coder reliability ensured the trustworthiness of findings.

\section{Understandings of the Rationale for ILEs}

All school leaders in the study understood that economic, social and technological developments were driving educational change, however, the depth of the leaders' understandings of ILEs differed and the nature of their understanding influenced how they supported the teachers in their schools.

In the school where teachers made the biggest transition to ILEs (School One), the school leaders shared a mutual understanding that traditional models of teaching and learning were no longer adequate to equip students. The leaders' rationale for change was that students would need twenty-first-century learning skills to survive and thrive in an unknown future. The leaders in School One also understood that leading change necessitated engaging in dialogue with staff about their understandings and how they aligned with the school vision. Rather than pontificating about the world changing and the need to be "leading edge", these school leaders focused on why they perceived ILEs could better suit their learners. The leaders referred to the guiding principles of ILEs and provided literature on twenty-first-century learning competencies. Teachers were encouraged to share their understanding of ILEs and their perceptions of risk engaging in practices that promote the principles of ILEs.

How the School One leaders discussed the rationale for change influenced the teachers' engagement. Through ongoing discussions about the rationale of ILEs many teachers were able to articulate deep understanding of ILEs. Having opportunities to engage in dialogue about the reasoning for the shift to ILEs enabled teachers to question their pre-existing conceptions about teaching and learning and to think through the implications for their beliefs, values and pedagogies (Hargreaves, 1994). Such discussions enabled many of the teachers to consider the possible benefits to students' learning if they stepped away from their familiar and "safe" teaching methods.

The professional conversations about ILEs had an additional benefit of enabling many of the teachers to develop a deeper level of collegial trust. Having opportunities to share perceptions of risk, and having these acknowledged by the school leaders, empowered the teachers to step into a degree of uncertainty and engage in the change process. This finding supports conclusions drawn in Twyford's (2016) study that found supportive relationships were essential for teachers to take risks when they lacked confidence or were uncertain in their state of knowledge.

In contrast, the school leaders in School Two and School Three could not articulate a clear rationale for why there was a global drive to establish ILEs. One of these school leaders expressed her perception that promoting student agency while being responsive to students' motivations could distract teachers from the "essence of education, what is important to learn". The other leader perceived it to be the teachers' 
(not the leaders') professional responsibility to unpack what "innovative" could look like for their students. Discussions about why ILEs may better suit the needs of twenty-first-century learners were absent in both of these schools. Instead, conversations focused on teachers' perceptions of what ILEs should look like. Circumventing conversations with leaders about the rationale for change resulted in many teachers in these schools focussing on surface features such as furniture while maintaining vague, inaccurate or conflicting understandings of the underlying principles of ILEs.

The ways teachers engage in new initiatives are shaped by their personal practical theories (Maaranen et al., 2016). Teachers use their past experiences and existing knowledge to notice, construe, construct and implement change (Spillane, 1999). In the context of ILEs, if teachers have limited experience or knowledge of the guiding principles of ILEs they may struggle to effectively engage in innovative practices. School leaders need to be aware of teachers' pre-existing frames and existing knowledge and provide professional support to enable teachers to develop shared, and accurate, understandings of ILEs. Obviously, this is problematic if leaders themselves cannot articulate a clear rationale for ILEs.

\section{Developing Expectations to Engage in ILEs}

When teachers understood why they were being expected to engage in ILEs, and how or what to change, they were more willing to take risks, tolerate uncertainty and explore new practices. Teachers' reactions were also generally more positive when they were provided with autonomy and control of the change process and when they had opportunities to work with school leaders to clarify expectations.

The leaders and teachers in School One, where change was most evident, worked together to generate expectations that they perceived could be achieved, and which aligned with the school's vision of ILEs. During meetings, the teachers discussed their understanding of ILEs and collated a list of innovative actions that they felt demonstrated their understanding. They discussed implications for practice and potential challenges that might thwart the success of the innovations. Through this process, the teachers worked alongside the leaders, they clarified and refined their understanding of ILEs and had opportunities to connect new theoretical learning with their existing pedagogical knowledge. These teachers had input into, and ownership of, the way ILEs were established in their school. The ongoing discussions made visible the potential merits of ILEs and also the challenges. The act of acknowledging the challenges and planning for them reduced many teachers' feelings of uncertainty. Establishing clear expectations did not completely mitigate these teachers' perceptions of risk but resulted in them working towards achieving the expectations and feeling more positive about exploring ways to work in ILEs. 
For decades, scholars have emphasised the importance of teachers perceiving themselves to be change agents and having a level of control over the change process for educational reform to be successful (Fullan, 2011; Hargreaves, 2004). When teachers lack an understanding of what, why or how to change, and perceive that they are viewed only as implementers, the implementation will often be superficial (Ungar, 2016). Such superficial engagement was evident in the two schools where the rationale for ILEs and expectations were not understood, transparent or shared.

\section{Supporting Teachers to Engage in ILEs}

Targeted professional learning support may increase teachers' engagement in ILEs (Jones, 2018), however, teachers working in seemingly similar conditions may perceive forms of support differently. Different perceptions of support were influenced by teachers' prior experiences, learning needs and perceptions of what constitutes professional support. This finding highlights how fundamentally complex educational change can be, and supports Ungar's (2016) suggestion that school leaders offer teachers different forms of support depending on teachers' needs and the needs of their students.

School leaders who make tactical choices about the professional learning available to teachers are in a better position to support teachers to engage in ILEs. In School One, leaders understood that teachers could be distracted by extraneous professional learning. Consequently, they identified which professional learning initiatives should be prioritised and which should cease. The leaders in this school also accepted that teachers were at different stages of comfort, transitioning from traditional practices to ILEs, and had different learning needs. To better support the teachers' individual needs, the leaders encouraged the teachers to source professional learning that they perceived would assist them to develop their understandings of ILEs. The teachers valued the opportunity to self-select what they perceived to be of value to their specific needs and context.

In contrast, leaders in Schools Two and Three implemented a one-size-fits-all approach to professional learning. These programmes consisted of a multitude of unrelated and episodic professional learning sessions which did not take into account the different needs of the teachers. The fragmented, short-term professional learning sessions resulted in a disjointed diffusion of effort. Furthermore, teachers in these schools lacked an understanding of how the professional learning connected to the school vision and described feeling overloaded, uncertain, frustrated and ultimately disengaged from the change process.

In addition to the extensive professional learning, teachers in Schools Two and Three were expected to explore innovative practices in collaborative professional inquiries. The literature on professional collaborative inquiries points to key characteristics of effectiveness. These characteristics include shared values and vision, collective responsibility, clear expectations, promotion of group and individual learning, and a culture of collaboration within the school (DeLuca et al., 2015). It 
was evident in this study that most of these characteristics for effective collaboration were absent. Inquiry meetings consisted of teachers having congenial conversations that focused on sharing stories of practice and suggestions for adapting practices. Nelson, Deuel, Slavit, and Kennedy (2010) caution that when teachers have superficial conversations about practice, "fault lines can be avoided because an examination of the value of those ideas remains private" (p. 176). However, the lack of professional probing into practice resulted in teachers not inquiring deeply into their practice or that of their colleagues.

Supporting teachers to shift from "congenial but relatively superficial conversations to dialogue that is more productive for improving student learning entails risk-taking and trust" (Nelson et al., 2010, p. 176). Nelson et al. (2010) suggest that intentional and transparent actions are required to enable teachers to engage in substantive and specific dialogue about teaching and learning. Teachers require support to learn how to have productive conversations, reflect on evidence and act.

\section{Revisiting Perceptions of Risk and Uncertainty}

Teachers were hesitant to use the term "risk" to describe their reactions to expectations to engage in ILEs. A teacher explained, "risk sounds dangerous, I don't think there is danger". Instead, teachers described feeling concerned or uncertain about engaging in ILEs, reactions they perceived to be less severe. As discussed earlier, uncertainty is inherent to perceptions of risk. Uncertainty is a key element often associated with risk because there is uncertainty of an outcome, and uncertainty in the perceived probability of its outcome value (Trimpop, 1994).

Perceptions of risk or feelings of uncertainty were acknowledged by teachers in the three schools. Teachers were uncertain how to effectively monitor student learning and were uncertain how to establish close relationships with students and the students' families in ILEs. Teachers also expressed feeling uncertain of ways to work collaboratively with colleagues. Their feelings of uncertainty stemmed from being expected to work with colleagues who had different understandings of ILEs, different pedagogical practices, incompatible personalities or different interpretations of what collaboration entailed.

In summary, many teachers were uncertain whether the benefits of ILEs outweighed the challenges. However, teachers' perceptions of risk and feelings of uncertainty were mitigated when school leaders provided a clear rationale for why a shift to ILEs might better suit twenty-first-century learners, and provided with explicit expectations of what or how to change, and targeted support to engage in ILEs. As Dinham (2000) explains, "often, it is not change per se that is the problem for teachers and schools, but the way that change is introduced" (p. 32). 


\section{Implications for Policy and Practice}

Enacting change "requires tremendous sophistication as well as some risk-taking" (Fullan, 2007, p. 2). It demands leadership with a clear understanding of the rationale for innovation and the capacity to lead change. The school leader's role is generally accepted as being "a central component in securing and sustaining school improvement" (Muijs \& Harris, 2003, p. 437), and it is pivotal in situations when an externally mandated reform, such as ILEs, is being imposed. Leaders in this study who understood why a shift to ILEs might better suit the needs of twenty-first-century learners were able to "create a fit between policy and practice, or at least lessen the misfit" (Razzaq \& Forde, 2013, p. 67). Managing change by integrating it with the priorities of their context and engaging in ongoing dialogue about the change enabled the school leaders and teachers in School One to work more purposefully. This reduced teacher perceptions of risk. Portoghese et al. (2012) state that providing changerelated information is fundamental to the success of any reform. Information can mitigate feelings of uncertainty and anxiety, which is essential for creating openness towards change initiatives: "Information is crucial in shaping employees' expectations and providing a basis for developing attitudes (positive and negative) toward change" (Portoghese et al., 2012, p. 584). This reflects the situation in School One.

In contrast, findings from Schools Two and Three indicate that leaders who cannot articulate the rationale for change, align their reasoning with realistic and explicit expectations, and remove distractions will struggle to motivate teachers to engage in ILEs. From this research, one could point the finger of blame at school leaders, however, a better solution may be to use a wider lens. If policymakers, professional learning facilitators, school leaders and teachers work together to understand the different challenges of implementing ILEs and design ways ILEs can be implemented, student outcomes are more likely to improve.

Acknowledgements Data utilised in this research was obtained in adherence to the required ethical protocol of the author's host institution. All images and diagrams are the property of the author, or the author has obtained consent to use them from the appropriate copyright owner.

\section{References}

Aven, T., \& Renn, O. (2009). On risk defined as an event where the outcome is uncertain. Journal of Risk Research, 12(1), 1-11. https://doi.org/10.1080/13669870802488883.

Baylor, A. L., \& Ritchie, D. (2002). What factors facilitate teacher skill, teacher morale, and perceived student learning in technology-using classrooms? Computers \& Education, 39(4), 395-414. https://doi.org/10.1016/S0360-1315(02)00075-1.

DeLuca, C., Shulha, J., Luhanga, U., Shulha, L. M., Christou, T. M., \& Klinger, D. A. (2015). Collaborative inquiry as a professional learning structure for educators: A scoping review. Professional Development in Education, 41(4), 640-670. https://doi.org/10.1080/19415257.2014.933120. 
Dinham, S. (2000). Teacher satisfaction in an age of change. In S. Dinham \& C. Scott (Eds.), Teaching in context (pp. 18-35). Camberwell, VIC: The Australian Council for Educational Research.

Dumont, H., Istance, D., and Benavides, F. (Eds.). (2010). The nature of learning: Using research to inspire practice. Educational research and innovation. Paris: OECD Publishing. https://doi. org/10.1787/9789264086487-en.

Fielding, R., \& Nair, P. (2005). The language of school design: Design patterns for 21st century schools. Minneapolis: The National Clearinghouse for Educational Facilities and The Knowledge Works Foundation.

Fullan, M. (2001). The new meaning of educational change. London: Routledge.

Fullan, M. (2007). The new meaning of educational change (3rd ed.). New York: Teachers College Press.

Fullan, M. (2011). Choosing the wrong drivers for whole system reform. Melbourne, Australia: Centre for Strategic Education.

Hargreaves, A. (1994). Changing teachers, changing times: Teachers' work and culture in the postmodern age. New York: Teachers College Press.

Hargreaves, A. (2004). Inclusive and exclusive educational change: Emotional responses of teachers and implications for leadership. School Leadership and Management, 24(3), 287-309. https:// doi.org/10.1080/1363243042000266936.

Jones, T. K. (2014). Theories of risk-taking and primary teachers' engagement in professional learning for change. Dissertation submitted in partial fulfilment of the degree of Master of Education. New Zealand, University of Auckland.

Jones, T. K. (2018). Working in wonderland; teachers' reactions to innovative learning environments. Unpublished doctoral thesis, University of Auckland, Auckland, New Zealand.

Le Fevre, D. M. (2014). Barriers to implementing pedagogical change: The role of teachers' perceptions of risk. Teaching and Teacher Education, 38, 56-64. https://doi.org/10.1016/j.tate.2013. 11.007.

Levin, B. B., He, Y., \& Allen, M. H. (2013). Teacher beliefs in action: A cross-sectional, longitudinal follow-up study of teachers' personal practical theories. The Teacher Educator, 48(3), 201-217. https://doi.org/10.1080/08878730.2013.796029.

Maaranen, K., Pitkäniemi, H., Stenberg, K., \& Karlsson, L. (2016). An idealistic view of teaching: Teacher students' personal practical theories. Journal of Education for Teaching, 42(1), 80-92.

Muijs, D., \& Harris, A. (2003). Teacher leadership-Improvement through empowerment? An overview of the literature. Educational Management \& Administration, 31(4), 437-448. https:// doi.org/10.1177/0263211X030314007.

Nelson, T. H., Deuel, A., Slavit, D., \& Kennedy, A. (2010). Leading deep conversations in collaborative inquiry groups. The Clearing House: A Journal of Educational Strategies, Issues and Ideas, 83(5), 175-179. https://doi.org/10.1080/00098650903505498.

OECD. (2017). The OECD handbook for innovative learning environments. Paris: OECD Publishing.

Ponticell, J. A. (2003). Enhancers and inhibitors of teacher risk taking: A case study. Peabody Journal of Education, 78(3), 5-24. https://doi.org/10.1207/S15327930PJE7803_02.

Portoghese, I., Galletta, M., Battistelli, A., Saiani, L., Penna, M. P., \& Allegrini, E. (2012). Changerelated expectations and commitment to change of nurses: The role of leadership and communication. Journal of Nursing Management, 20(5), 582-591. https://doi.org/10.1111/j.1365-2834. 2011.01322.x.

Razzaq, J., \& Forde, C. (2013). The impact of educational change on school leaders: Experiences of Pakistani school leaders. Educational Management Administration \& Leadership, 41(1), 63-78. https://doi.org/10.1177/1741143212462698.

Richardson, V. (1990). Significant and worthwhile change in teaching practice. Educational Researcher, 19(7), 10-18. https://doi.org/10.3102/0013189X019007010.

Rosa, E. A. (1998). Metatheoretical foundations for post-normal risk. Journal of Risk Research, l(1), 15-44. https://doi.org/10.1080/136698798377303. 
Spillane, J. P. (1999). External reform initiatives and teachers' efforts to reconstruct their practice: The mediating role of teachers' zones of enactment. Journal of Curriculum Studies, 31(2), 143175. https://doi.org/10.1080/002202799183205.

Stulz, R. M. (1996). Rethinking risk management. Journal of Applied Corporate Finance, 9(3), 8-25. https://doi.org/10.1111/j.1745-6622.1996.tb00295.x.

Trimpop, R. M. (1994). The psychology of risk taking behaviour. Amsterdam: North-Holland.

Twyford, K. (2016). Risk or resistance: Understanding teachers' perceptions of risk in professional learning. Doctoral thesis, University of Auckland, Auckland, New Zealand.

Twyford, K., Le Fevre, D., \& Timperley, H. (2017). The influence of risk and uncertainty on teachers' responses to professional learning and development. Journal of Professional Capital and Community, 2(2), 86-100. https://doi.org/10.1108/JPCC-10-2016-0028.

Ungar, O. A. (2016). Understanding teachers' attitude toward educational reforms through metaphors. International Journal of Educational Research, 77, 117-127. https://doi.org/10.1016/ j.ijer.2016.03.008.

Tamara Jones (NZ) Tamara is an Assistant Principal with over twenty years' experience in the primary sector. Her $\mathrm{PhD}$ research explored teachers' perceptions of risk associated with the transition to Innovative Learning Environments, and forms of support which mitigate perceptions of risk and increase engagement.

Deidre Le Fevre (NZ) is an Associate Professor in the Faculty of Education and Social Work at the University of Auckland in New Zealand.

Open Access This chapter is licensed under the terms of the Creative Commons Attribution 4.0 International License (http://creativecommons.org/licenses/by/4.0/), which permits use, sharing, adaptation, distribution and reproduction in any medium or format, as long as you give appropriate credit to the original author(s) and the source, provide a link to the Creative Commons license and indicate if changes were made.

The images or other third party material in this chapter are included in the chapter's Creative Commons license, unless indicated otherwise in a credit line to the material. If material is not included in the chapter's Creative Commons license and your intended use is not permitted by statutory regulation or exceeds the permitted use, you will need to obtain permission directly from the copyright holder.

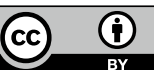

